\title{
Process Evaluation of a Mixed Methods Feasibility Study to Identify Hospital Patients with Palliative Care Needs in Portugal
}

\author{
Avaliação de Processo de um Estudo de Viabilidade de \\ Metodologia Mista para Identificar Doentes Hospitalares com \\ Necessidades de Cuidados Paliativos em Portugal
}

\author{
Bárbara ANTUNES ${ }^{1,2,3}$, Pedro PEREIRA RODRIGUES ${ }^{2,4}$, Irene J. HIGGINSON ${ }^{5}$, Pedro LOPES FERREIRA ${ }^{2}$ \\ Acta Med Port 2022 Feb;35(2):94-104 - https://doi.org/10.20344/amp.15294
}

\section{ABSTRACT}

Introduction: Evidence shows most patients are not recognised by their attending healthcare professionals as having palliative needs. This feasibility study aimed to aid healthcare professionals identify hospital patients with palliative needs.

Material and Methods: Mixed-methods, cross-sectional, observational study. The patient inclusion criteria comprised: age over 18 years old, being mentally capable to give consent judged as such by participating healthcare professionals, and if unable, having a legal substitute to consent, having a diagnosis of an incurable, potentially life-threatening illness. Field notes were taken for reflexive purposes. Outcome measures included: Integrated Palliative Care Outcome scale, surprise question, phase of illness, referral request status, The Eastern Cooperative Oncology Group Performance Status and social needs assessment. An interim data collection period meeting assessed implementation outcomes in each context. A web-based survey was sent to all participating healthcare professionals at the end of data collection period to explore overall experiences of participation and implementation outcomes.

Results: Forty-two departments in four hospitals were contacted. The study was presented in nine departments. The field notes were vital to understand the recruitment process and difficulties experienced: time constraints, fear of additional work, department dynamics and organisation, relationships between departments and need of training in palliative care and research. One department agreed to participate. There were six participating healthcare professionals and only 45 patients included. Three participating healthcare professionals responded to the web-based survey.

Conclusion: There is an urgent need to provide generalist palliative care training to clinicians.

Keywords: Decision Making; Health Services Research; Implementation Science; Medical Education; Palliative Care; Patient-centered Care

\section{RESUMO}

Introdução: A maioria dos pacientes não são reconhecidos pelos seus profissionais de saúde como tendo necessidades paliativas. Este estudo de viabilidade visou ajudar os profissionais de saúde a identificar doentes hospitalares com necessidades paliativas.

Material e Métodos: Método misto, transversal e observacional. Os critérios de inclusão dos doentes compreenderam: idade igual ou superior a 18 anos; capacidade mental para dar consentimento informado, avaliado pelos profissionais de saúde participantes ou, caso não tenham essa capacidade, presença de um representante legal para consentir; ser portador de doença incurável, ameaçadora do tempo de vida. As notas de campo serviram fins reflexivos. As medidas de resultados utilizadas foram: escala integrada de cuidados paliativos, pergunta surpresa, fase da doença, estatuto de pedido de encaminhamento, Estado de Desempenho do Grupo de Oncologia Cooperativa Oriental (ECOG) e avaliação das necessidades sociais. A reunião intercalar no período de recolha de dados auxiliou-nos a avaliar os resultados da implementação em cada contexto. No final do período de recolha de dados enviámos um inquérito eletrónico aos profissionais de saúde participantes para explorar experiências globais de participação e resultados de implementação. Resultados: Contactámos 42 serviços em quatro hospitais. Apresentámos o estudo em nove serviços. As notas de campo foram vitais para compreender o processo de recrutamento e as dificuldades vividas: restrições de tempo, medo de trabalho acrescido, dinâmica de serviços e organização, relações entre serviços e necessidade de formação em cuidados paliativos e investigação. Contámos com a participação de um serviço, seis profissionais de saúde e 45 doentes. Três profissionais de saúde participantes responderam ao inquérito eletrónico.

Conclusão: É urgente a formação em cuidados paliativos generalistas a médicos que trabalham em hospitais.

Palavras-chave: Assistência Centrada no Doente; Ciência da Implementação; Cuidados Paliativos; Educação Médica; Investigação sobre Serviços de Saúde; Tomada de Decisão

\section{INTRODUCTION}

Most people with an advanced disease would benefit from palliative care $(P C)$ interventions from the moment of diagnosis..$^{1,2}$ Evidence shows that most people with an advanced disease are not recognised as such by their health-

do get referred are in the last weeks of life. ${ }^{3}$

Tools have been and continue to be developed worldwide to aid healthcare professionals identify patients in need and their families earlier in the disease trajectory, care professionals across all levels of care and those who thus potentially promoting access to this type of care to all

1. Primary Care Unit - Department of Public Health and Primary Care. University of Cambridge. Cambridge. United Kingdom.

2. Centre for Health Studies and Research. Coimbra. Portugal.

3. Centre for Health Technology and Services Research. Porto. Portugal.

4. Faculty of Medicine of University of Porto. Porto. Portugal.

5. King's College London. Cicely Saunders Institute - Department of Midwifery and Palliative Care. Florence Nightingale School of Nursing. London. United Kingdom.

$\triangle$ Autor correspondente: Bárbara Antunes. bc521@medschl.cam.ac.uk

Recebido: 11 de novembro de 2020 - Aceite: 03 de março de 2021 - First published: 17 de agosto de 2021 - Online issue published: 01 de fevereiro de 2022

Copyright $\odot$ Ordem dos Médicos 2022 
patients who need it, and improving opportunities for integrated care. . $^{-9}$

There is no consensus on the best PC needs identification tools to use. ${ }^{10}$

Seven tools were found to identify patients with PC needs in primary care, Europe wide, but none were validated or widely implemented. ${ }^{5}$

Even though there are a few promising measures using predictive scores in the hospital setting, they aren't yet considered optimal as they do not help making decisions on patients whose PC needs are not or are falsely identified. Implementation in clinical practice is challenging and most studies are published as academic work. ${ }^{4,8,11} \mathrm{~A}$ systematic process has defined key primary and secondary criteria to screen patients upon admission, every day during hospital stay and how to improve discussion around continuity of care with other healthcare institutions upon discharge. ${ }^{9}$ Indeed, the World Health Organization defines integration as "combining different kinds of (...) services or operational programs to ensure and maximize collective outcomes. It would include referrals from one service to another and is based on the need to offer comprehensive services". ${ }^{12}$ Nevertheless, those criteria should be adapted to the local context. ${ }^{9}$ Authors also point out that not all clinicians are able to make a basic PC needs assessment and educational initiatives are warranted. Finally, substantial barriers to implementation are described, mainly attitudinal and logistical. This is well aligned with findings from a scoping review of use of complexity theory in health services research: "... the included studies captured how diverse relationships and communication between agents of a system can influence unpredictable changes within the system ${ }^{13}$ and with the non-adoption, abandonment, scale-up, spread, and sustainability (NASSS) framework, an evidence-based, theory-informed, and pragmatic framework to help predict and evaluate the success of a technology-supported health or social care program, which takes into account that..." it is not individual factors that make or break a technology implementation effort but the dynamic interaction between them". ${ }^{14}$ The framework consists of 13 questions across six domains: 1 ) the condition (1A: nature of condition or illness, 1B: comorbidities, socio-cultural influences), 2) technology (2A: material features, $2 \mathrm{~B}$; type of data generated, $2 \mathrm{C}$ : knowledge needed to use, 2D: techology supply model), 3) value proposition ( $3 A$ : supply-side value to developer, 3B: demand-side value to patient), 4) the adopter system (4A:staff role, identity, 4B: patient simple versus complex input, 4C: carers available, nature of input), 5) health or care organization(s) (5A: capacity to innovate, including leadership, 5B: readiness for this technology/change, 5C: nature of adoption/funding decision, 5D: extent of change, to daily activities which become routine and the extent of those changes that are required in order for new routines to be to implemented, 5E: work needed to implement change), 6) the wider system (6A: political/policy, 6B: regulatory/legal, 6C: professional, 6D: socio-cultural) and 7) embedding and adaptation over time (7A: scope for adaptation over time,
7B: organisational resilience). Authors point out that the framework is intended to be used reflexively to guide conversations and help generate ideas, rather than be used as a checklist.

This paper describes the process evaluation of a feasibility study to aid healthcare professionals identify hospital patients with PC needs. The specific objectives are (a) to explore how participating healthcare professionals (PHP) experience the use of the selected measures, (b) to understand missing data occurrence and (c) to explore the occurrence of implementation outcomes, namely, acceptability (perception among stakeholders that an intervention is agreeable), adoption (intention, or action to try to employ a new intervention), appropriateness (perceived fit or relevance of the intervention in a particular setting or for a particular target audience or issue), feasibility (extent to which an intervention can be carried out in a particular setting), fidelity (degree to which an intervention was implemented as it was designed in an original protocol, plan, or policy), coverage (degree to which the population that is eligible to benefit from an intervention actually receives it) and sustainability (extent to which an intervention is maintained or institutionalized in a given setting). ${ }^{15,16}$

\section{MATERIAL AND METHODS}

This was a mixed-methods, cross sectional feasibility study, ${ }^{17-19}$ which is a kind of pilot study that is designed to systematically address the different dimensions of feasibility to determine whether a larger definitive trial is likely to be successful in testing the intervention.

Patient inclusion criteria were as follows: eighteen years of age and over, being mentally fit to give consent judged by the PHP, and if unable, have a legal substitute to consent, and having a diagnosis of an incurable, potentially lifethreatening illness.

The recruitment procedures included searching online for email contacts of hospital departments and then establishing contact.

The emails that were sent provided information about the existence of the study, requested a meeting to present it locally and invited departments to participate. The 15-minute presentation was divided in two parts: first, briefly define PC and its importance, distinguish palliative from end-of-life care, discuss generalist and specialist PC; second, describe the aim, objectives, procedures and expected results/possible benefits of the study. Each email had two follow-ups as reminders with an interval of two weeks. If we got no reply, we would no longer follow-up with the department by email. Nevertheless, once we started presenting the study in consenting departments, we went in person to those that had not replied and asked for a meeting. The hospital setting was chosen because it is well known to have high numbers of patients with palliative needs and because all contacted hospitals were relatively close to each other, and hence manageable to visit by the researcher. This was important given the low resources available.

A standard operating procedures manual was developed 
and distributed to the facilitator PHP leading the study locally (Appendix 1: https://www.actamedicaportuguesa.com/ revista/index.php/amp/article/view/15294/Appendix_01. pdf). PHPs screened potential participants, explained the study, got written consent, and completed the questionnaire regarding the patient's needs.

One meeting was held during the interim data collection period between PHPs and one member of the research

Table 1 - Description of measures used in the study

Data collected by research team member

Researcher field notes ${ }^{21-23}$

This method records unique cultural and social situations, including individual aspects of healthcare professionals and their interactions, considering the complexities of health services research. The aim of these field notes was for reflexive purposes. The researcher (BA) has had formal training in this methodology. Field notes were taken consistently immediately after each meeting with potential participating services and include descriptive and critical reflective information and some exact quotes.

Data collection performed by participating healthcare professionals in relation to the patients

The Portuguese version of the Integrated Palliative care Outcome Scale (IPOS) reported by the health care professional ${ }^{24-27}$

The one-year surprise question ${ }^{28}$

Phase of illness ${ }^{29}$

Referral request to the hospital based palliative care team status measure

The Eastern Cooperative Oncology Group (ECOG) Performance Status ${ }^{20}$

Social needs dichotomised measure
This measure is used in many countries and has been adapted and validated in over 10 languages. It has also been culturally adapted and validated to European Portuguese. IPOS is a brief, 18-item, multidimensional scale that captures core concerns in palliative care. The first item is an open question on the three main problems or worries the patient might have had in the past week (results are not presented in this study); items 2 to 9 are set on a 5 point Likert scale based on descriptors (zero - not at all, 1 - slightly, 2 - moderately, 3 - severely, 4 - overwhelmingly), item two is a list of 10 of the most common physical symptoms in a palliative population, with the possibility of adding up to three more symptoms which are not present in the list (results are not presented in this study); item 3 pertains to anxiety, item 4 asks about family/friends worry, item 5 is on depression; item 6 is about being at peace; item 7 relates to sharing feelings with significant people; item 8 is about information needs and item 9 concerns practical problems related to their illness.

This measure has been culturally adapted and validated to European Portuguese. This is a one item measure directed at the clinician: "Would you be surprised if this patient died in the next year?" In this study a negative response should trigger the consideration of referring the patient to palliative care considering the results of the remaining measures, rather than for predicting mortality.

This measure is a concept developed in the context of the Australian Case Mix Classification describing the stage of a patient's illness in five clinically meaningful phases-stable, unstable, deteriorating, terminal, bereavement - the latter was not used in the present study. This assessment provides participating healthcare professionals with a clinical picture of a patient trajectory, including a distinction between expected and unexpected fluctuations of the patients' phase of illness, which might trigger changes to the care plan.

This was developed for the study. Based on the fast-track trial typology "urgent/non-urgent", ${ }^{30}$ we developed the question "Has a referral to palliative care been made?" to which the answer has five descriptive levels: yes, urgent; yes, not urgent; no; in doubt, to be discussed in team meeting; already followed by palliative care.

ECOG describes a patient's level of functioning in terms of their ability to care for themselves, daily activity, and physical ability. It has 6 descriptive levels: from zero, which is fully active, to 5 , which is death. Participating healthcare professionals have used this measure in practice for years to assess the level of functioning and felt so comfortable in its use they requested for the data collection form to present a space for ECOG assessment only, rather than the full measure, as they use it from memory.

Participating healthcare professionals requested for a yes/no item answering the question "Do I feel this patient has social needs?"

\section{Data collection answered by participating healthcare professionals in relation to participating in the feasibility study}

Web-based survey ${ }^{31}$

The web-based survey was developed specifically for this study to explore the overall experience of participation, including usefulness of data collected in real time and how it was used, as well as, to assess all implementation outcomes. It was sent to participating healthcare professionals at the end of data collection period. The Checklist for Reporting Results of Internet E-Surveys (CHERRIES) was followed. We used Google Form and all answers were anonymised. The survey was tested twice before sending to potential respondents. A total of five reminders were used during the subsequent two months. The introductory text explained what the web-based survey pertained to (even though participating healthcare professionals knew they would receive the invitation to respond), ensured anonymisation of data and stated that there were no right or wrong answers. There was a total of 25 items to respond. There was only one screen and participating healthcare professionals were required to scroll down to answer, to complete the survey. The survey never displayed a second time once the user had filled it in. To reduce missing data all fields were mandatory except the last item. There were no incentives offered. Verbal consent was obtained in the interim data collection meeting. 
team (BA) with the aim of allowing participating healthcare professionals to express their thoughts on variables that might be important to add and/or remove, based on their context and overall experience. For the purposes of clarity, namely to describe all the measures used in this section, we report that changes to the data collection form were indeed made accordingly after the meeting, namely, the Eastern Cooperative Oncology Group Performance Status $(E C O G)^{20}$ and one binary item on social needs were added.

Demographic and clinical data were collected. The date of death was requested eight months after the study collection period closed. Table 1 describes all the measures used.

Ethics committee approval was granted (approval number 107-2018-1 issued on the $19^{\text {th }}$ of July 2018 and authorization received on the $8^{\text {th }}$ of August 2018) by the Hospital Ethics Committee and was in accordance with the 1964 Helsinki declaration and its later amendments in 2013 or comparable ethical standards. ${ }^{32}$ All participants gave informed signed consent. Confidentiality and pseudo-anonymity were ensured for the participant's department. All patient data were coded by PHPs before being sent to the research team.

\section{Analysis}

Qualitative data from the researcher's field notes were kept as reported and have been translated by BA (Appendix 2: https://www.actamedicaportuguesa.com/revista/index. php/amp/article/view/15294/Appendix_02.pdf). Data were analysed deductively, following Thompson et al.'s attributes, namely, connections, communication, learning, adaptation, diversity, equilibrium, agents and unpredictability, ${ }^{13}$ and inductive thematic analysis was performed following these steps: familiarising with data (transcribing data, reading and rereading the data, noting down initial ideas), generating initial codes (coding interesting features of the data systematically across the entire data set, collating data relevant to each code), searching for themes (collating codes into potential themes, gathering all data relevant to each potential theme), reviewing themes (checking if the themes work in relation to the coded extracts and the entire data set, generating a thematic map), defining and naming themes (ongoing analysis for refining the specifics of each theme and the overall story that the analysis tells, generating clear definitions and names for each theme) and producing the report (final opportunity for analysis. Selection of vivid, compelling extract examples, final analysis of selected extracts, relating back of the analysis to the research question and literature, producing a report of the analysis). ${ }^{33}$

Descriptive statistics were used for demographic and clinical variables, and SPSS, version 24.0 (SPSS/IBM Corp., Armonk, NY, USA) software was used.

Data from the meeting during the interim data collection period were analysed using thematic analysis. ${ }^{33}$

Data from the web-based survey were translated and presented as reported by participants, (Appendix 3: https:// www.actamedicaportuguesa.com/revista/index.php/amp/ article/view/15294/Appendix_03.pdf).
This study is informed by the Medical Research Council Guidance on developing and evaluating complex interventions. ${ }^{35-37}$ We followed the MOREcare guidance for reporting. ${ }^{38}$

\section{RESULTS}

Four separate data sources were collected: field notes of hospital departments that were contacted (Appendix 2: https://www.actamedicaportuguesa.com/revista/index.php/ amp/article/view/15294/Appendix_02.pdf); patient data; meeting during the interim data collection period and webbased survey (see Appendix 3: https://www.actamedicaportuguesa.com/revista/index.php/amp/article/view/15294/ Appendix_03.pdf). Results are presented following the chronological order of events.

A total of 42 departments in four hospitals were contacted by service directors' emails. Fourteen replied and nine agreed to a meeting to present the study and were invited to participate. Six services in two hospitals informally agreed to participate right after the presentation but did not participate. There was one participating service which collected patient data. Given the sensitive nature of some data collected, the institution will remain anonymous.

The main themes emerging were time constraints, fear of added work, service dynamics and organisation, relationships within each service, relationships between services, ethical dilemmas regarding referring patients to PC services and training needs in PC and research. It is worth mention that a few services had given up on referring patients as the response from the PC service came late and clinicians felt they were failing patients and families. Hence, for most patients the decision was not to refer and try to manage issues, despite acknowledging their lack of training in PC (Appendix 2: https://www.actamedicaportuguesa.com/revista/index.php/amp/article/view/15294/ Appendix_02.pdf).

Patient data were collected between the $2^{\text {nd }}$ November 2018 and the $21^{\text {st }}$ February 2019 at one ambulatory oncology department of a major hospital. A total of 1495 patients were seen in this period in 2388 medical consultations with 12 doctors. Six doctors agreed to enter the study. Forty-five patients were included, and $58 \%$ were male. The mean age of the sample was 65 years old (SD 11.2), and approximately half, $23(51 \%)$ lived in an urban area and 14 had 4 years of formal education (31.1\%). Most participants, 26 (57.8\%) had not been admitted to hospital in 2018. Concerning the Integrated Palliative Care Outcome Scale (IPOS), the items scoring highest were patient anxiety, family anxiety and sharing feelings. Social needs were considered to exist in three $(33.3 \%)$ patients out of eight (data collected after the meeting in the interim data collection period). ECOG data were missing in relation to two patients (25\%). Eight months after the end of data collection, $19(42.2 \%)$ patients had died (Table 2).

The meeting during the interim data collection period was held on the $19^{\text {th }}$ December 2018. Notes are categorised according to the following main themes (Table 3): 


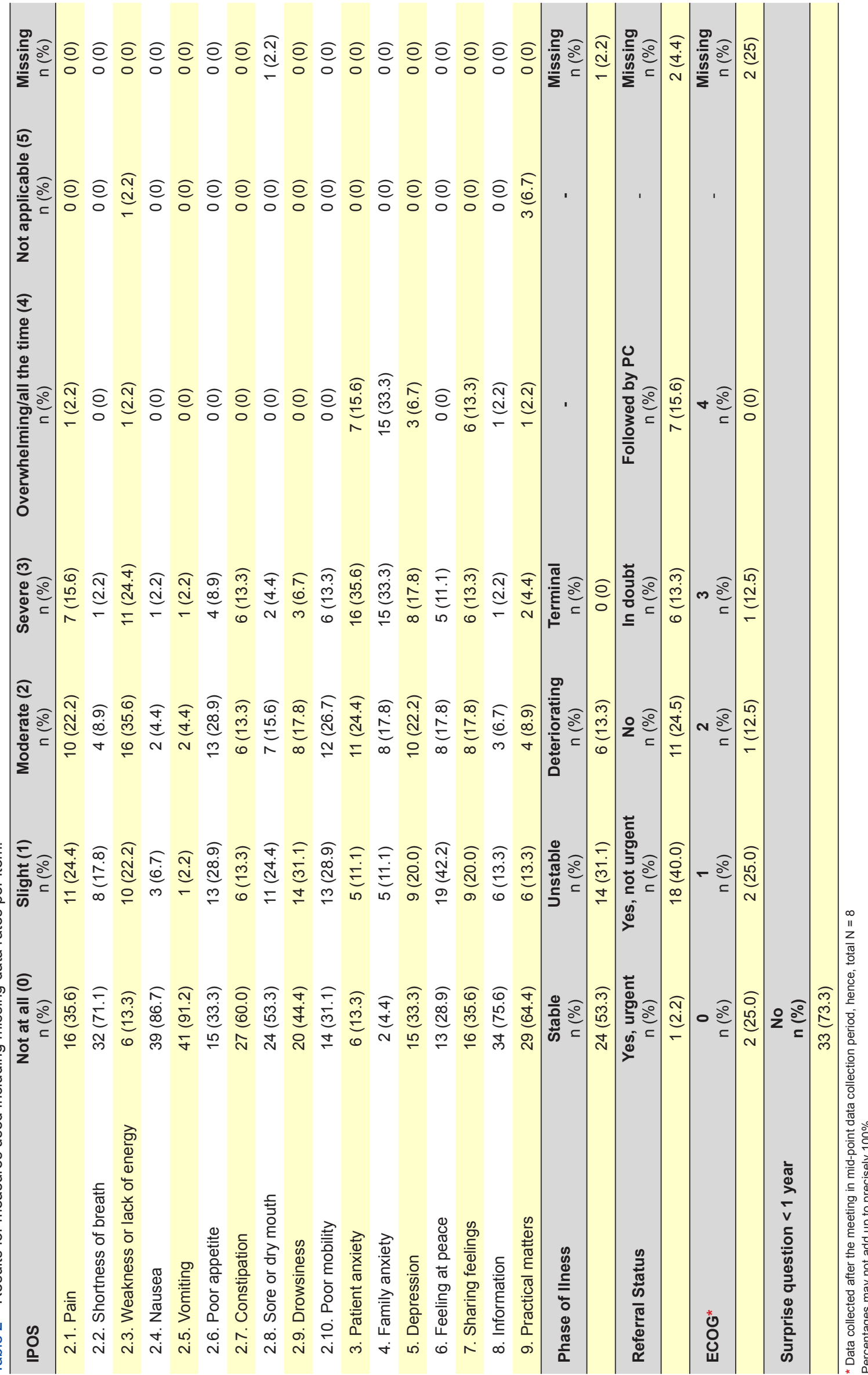


usefulness of variables in data collection form, managing patients identified with PC needs, dealing with knowledge provided by the data collection, time constraints during clinical consultation, personal experience in being PHPs and discussing changes to the data collection method.

The web-based survey was sent on the $9^{\text {th }}$ April 2019. Of the six PHPs, three answered (50\% response rate), all female, mean age was 36 years old, all oncologists worked in the department between five and nine years. One had a post-graduation course in PC (\#1) and two had had more than 30 hours of training in PC. Data are translated and presented as reported by participants (see Appendix 3: https:// www.actamedicaportuguesa.com/revista/index.php/amp/ article/view/15294/Appendix_03.pdf).

Overall, there seems to be a number of benefits in using IPOS alongside the other measures, namely, to alter PHPs' perception of identifying patients with $\mathrm{PC}$ needs and as a communication tool, as one PHP reveals how they used the questionnaire to objectively show a patient who had previously rejected referral to the PC team, and the respective family, that there were a number of physical and nonphysical issues occurring and that it would be better if those healthcare professionals would be involved in patient care. The patient agreed to be referred.

Regarding the implementation outcomes, based on the interim data collection period and the web-based survey data results, we consider that appropriateness, acceptability, fidelity and adoption were achieved, and feasibility, cov- erage and sustainability were not achieved.

Missing data occurrence was minimal, occurring in 4 items $(\min =2.2 \%, \max =25 \%$ ) caused by 'missed data item in questionnaire', 38 in which the PHP accidently skipped an item. This is known to happen more frequently in paper format. ${ }^{39}$

\section{DISCUSSION}

It may not come as a surprise that the only participating department in this study was an oncology department, and that, considering the modern PC movement started with oncology patients, all PHP had, at least, basic PC training. Our findings suggest that, in participating departments, the use of the patient centred outcome measures selected for this feasibility study to aid healthcare professionals identify patients with PC needs is characterized by its appropriateness, acceptability, fidelity and adoption. These can be identified as positive outcomes. Nevertheless, feasibility, coverage and sustainability were not achieved.

One of the main results of this study was the low participation rate. Contacting 42 hospital departments in four hospitals and having only one collecting data, shows how important it was to conduct a feasibility study.

Although field notes are subjective due to being dependent of the observer, in this study these data were vital to understand the recruitment process and the difficulties experienced. It is worth mentioning that field-notes are an important component of PC research, including the

Table 3 - Notes taken during the meeting in interim data period

\begin{abstract}
Usefulness of variables in data collection form: PHPs felt items were lacking for social needs and ECOG and requested that those would be added. The referral status measure was considered useful for the decision-making process.

Managing patients identified with palliative care needs: PHPs try to manage patients with palliative needs as much as possible, as they know the hospital based palliative team is understaffed. Many patients are discussed with the palliative team over the phone so that they don't refer them too early, as the palliative team would not accept them over more priority patients of other services. One PHP stated the measures helped alter their perception, in terms of identifying patients with palliative needs, two disagreed, but stated that phase of illness and IPOS physical items gave a systematic picture of needs, especially in patients with heart and renal comorbidities, which was helpful.
\end{abstract}

Dealing with knowledge provided by data collection: overall PHPs seemed to be more at ease with physical symptoms and not at all with non-physical symptoms, having verbalised they needed specific training to deal with expressions of patients and relatives regarding emotional needs and psychological and existential suffering. They needed a communication tool kit to best deal with those emotions, as well as their own emotions. One PHP describes feelings of anguish and frustration as they feel more might be done for patients and families, but due to time constraints and poor integration of services, they do not get all the help and care needed.

All PHPs reported to have benefits on patient care when using the measures, especially perception of concrete needs that otherwise were being overlooked.

Time constraints during clinical consultation: all six PHPs felt the time of consultation was longer by approximately 10 minutes, due to data collection form being used as an interview guide. This led to not all patients being properly screened, as PHPs perceived that patients they knew better, who already took a bit longer in the consultation, would be in there for too long.

Personal experience in being a PHP: two PHPs stated they would not be able to continue to collect data, for feeling increasingly stressed about time of consultations and apologised for dropping out of the study. The PHP leading the study locally explains that their working contract is $100 \%$ clinical. There is no contractual protected time for research or teaching, even though they do all three activities. Research is done mostly in their free time "... you see, we hardly have time to conduct our own research, so it is extremely difficult to participate in other studies, especially if we are directly participating, like in your study. And yours is so important, but as you can see, we already stay overtime for patient care and filling patient records, that we would only leave here at night!"

Discussing altering the data collection method: PHPs suggested giving data forms to patients (IPOS filled by patients) to fill at home and bring it to the next appointment. It would be more flexible and appointment time would be reduced. We agree that this is a possibility, but it will not take place. A third PHP will also drop out after this meeting. From this meeting until the end of data collection, 3 PHPs will collect data on 8 patients. 
implementation of feasibility studies, as they allow participants and researchers to revisit and critically reflect on their own experience. ${ }^{40}$ Indeed, field-notes included comments from PHP and observation of team dynamics, which allowed investigators to realize that departments within the same institution function in different ways. The relationship between each department and the specialised hospitalbased PC team is also different. ${ }^{41}$

Having different departments reporting the desire and need of generalist PC training was also an important finding, as was worrying about ethical issues regarding the nature of the study. A few departments had given up on referring patients as the response came late and clinicians felt they were failing patients and families. Hence, the decision was not to refer and try to manage issues, despite acknowledging their lack of training in palliative care. In fact, no matter how accurate a measure is in identifying patients with $\mathrm{PC}$ needs, access to and provision of PC must be available, whether generalist or specialist, since otherwise it may not be ethical to perform such identification. ${ }^{42,43}$ Ethically difficult situations may occur if healthcare professionals identify these needs but are not able to find the balance concerning the different demands, expectations and values that influence the care that is provided to those patients. Similar concerns were reported by Rasoal et al, ${ }^{44}$ who considered the impact of these needs, demands and expectations at the system, organisation and personal levels of all the stakeholders involved in the process of care.

Finally, while the international literature suggests the benefits of integrating PC in other healthcare settings (e.g., intensive care), ${ }^{3,45,46}$ it is with concern that we notice some existing misperceptions and misconceptions about PC among these professionals, such as “... in our intensive care unit there are no PC cases, only intensive care cases.". This is well aligned with a recent systematic review and narrative synthesis which revealed "... a medical culture of disengagement towards dying patients and varying attitudes of senior doctors." 47

Interestingly, patient data are well aligned with data from the field notes, as overall, physical symptoms scored lower, thus suggesting being best dealt with by PHPs, and anxiety and sharing feelings items scored the highest. PHPs reported not being at ease and having difficulties with these issues and even asked for training in these matters. Using IPOS systematically seemed to help PHPs to becoming aware of these difficulties.

Our study shows that there are barriers to conducting PC research in hospitals, particularly concerning the involvement of clinicians in the research process. Research is considered a key element of PC development and pivotal in ensuring evidence-based PC practices. In fact, the Portuguese Strategic Plan for the development of PC highlights research as a core element to be fostered..$^{39}$ However, the lack of contractual protected time for clinicians to combine both research and clinical practice and develop research competencies challenge the development and implications of studies relevant for clinical practice.

Despite only having three respondents, it appears that, overall, the measures used seemed to help alter clinicians' perceptions regarding patients with PC needs, thus aiding in the decision to refer earlier and contributed directly to improve communication between the clinician and both patient and families. In fact, patient centred outcome measures were never developed to substitute patient-carer communication. But they can be, amongst their many uses, a bridge to address that communicational gap, and therefore aiding the start of very important conversations which will allow patients and families to carry out their psychological, emotional and spiritual tasks in a benign way, culminating in an acceptance that all that there was to be lived, no matter in what shape or form, was hopefully lived. It is possible to train healthcare professionals to achieve this. These are skills that can be acquired with proper training.

Missing data occurrence was minimal, caused by "missed data item in questionnaire". ${ }^{38}$ This phenomenon could have been minimised if an electronic format was used, as shown by Oliveira and colleagues. ${ }^{39}$

To the best of our knowledge, this is the first feasibility study that combines the use of various measures, including patient centred outcome measures, in order to identify PC needs in Portuguese outpatients by their attending physicians. This design not only allowed us to achieve all three objectives, but also, by the additional use of field-notes and a web-based survey, also allowed us to identify many challenges occurring in clinical practice. Furthermore, achieving negative outcomes met the purpose of conducting a feasibility study and allowed us to identify barriers to research and develop strategies to address them in the future (Fig. 1).

Even though anecdotally one could argue that the issues encountered in this feasibility study are common to many hospitals, this study allowed us to collect data and add to the evidence on those issues. The main limitation in our study is the low participation rate. Additionally, the paper format data form took around 10 minutes to complete, given that PHPs used IPOS as an interview guide, and clinicians felt its impact on routine clinical care. An electronic format would be preferred. On the other hand, by selecting to use it like that, PHPs were much more aware of non-physical issues that otherwise would not be systematically explored. These were sensed by PHPs as relevant for patients and families. These results provide rich information for future attempts of conducting a full multicentre PC research study.

In 2003, the Council of Europe issued recommendations to all member states regarding PC and its status as an inalienable element of a citizen's right to health care. All member states were advised to make sure that PC is available to all those in need. In 2012, Portugal legislated provision of and access to PC at all care levels. Legislation states that all citizens have the right to timely access and high-quality palliative care interventions in all contexts of healthcare services, and clinicians working in non-specialised PC services are expected to provide generalist PC interventions. ${ }^{48}$ 


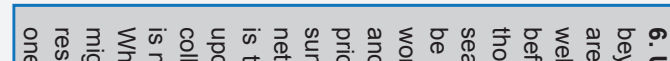

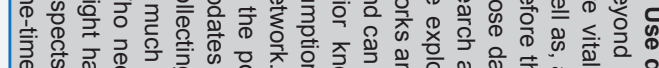

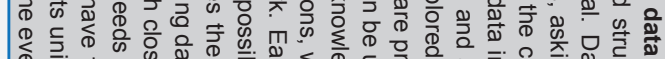

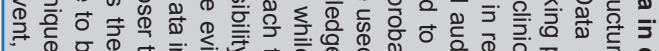
Fं

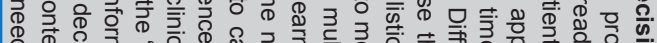

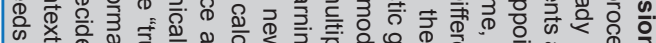

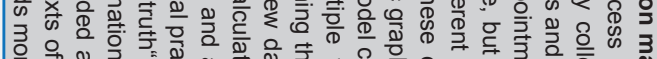

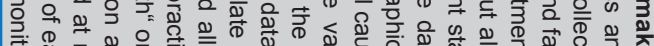

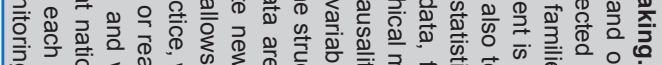

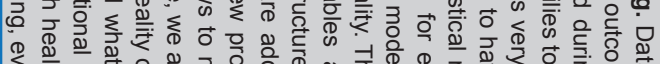

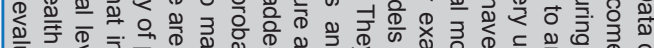

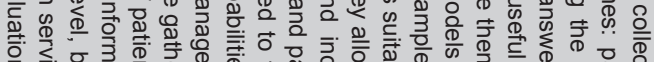

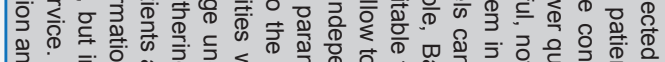

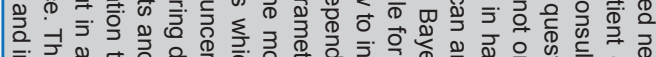

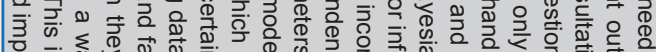

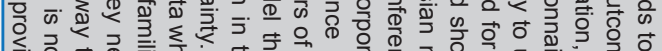

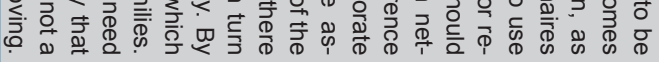

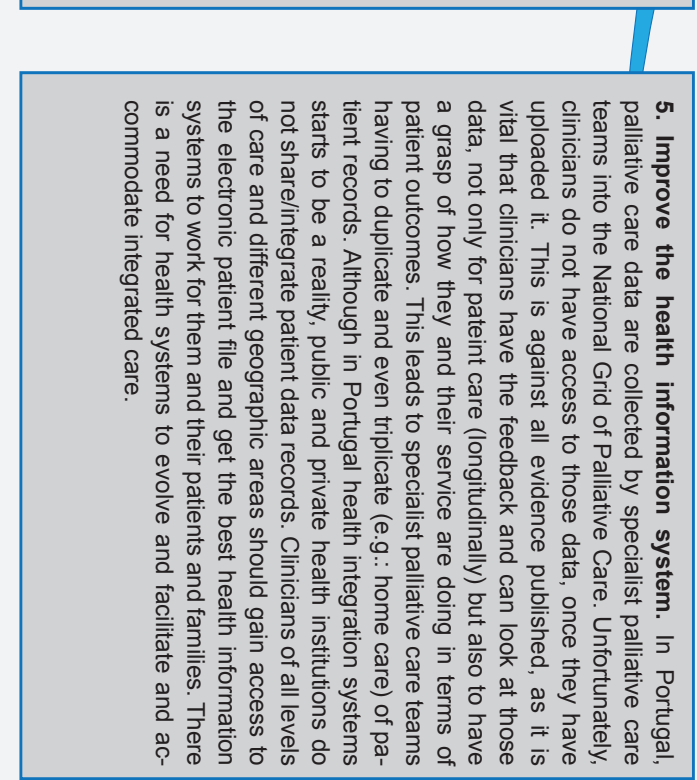

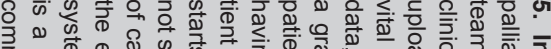

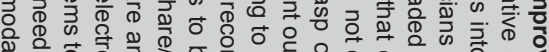

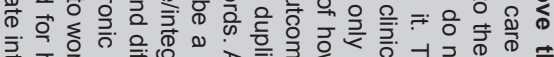

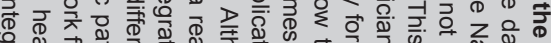

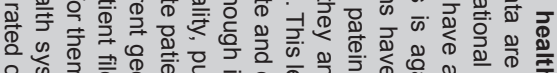

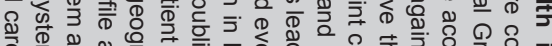

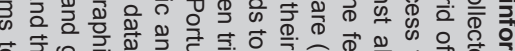
व

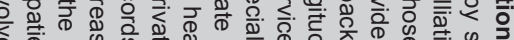

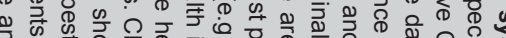

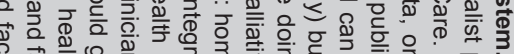

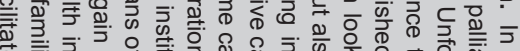

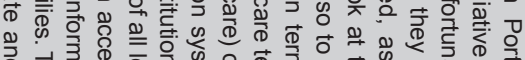

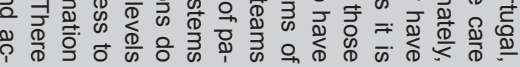

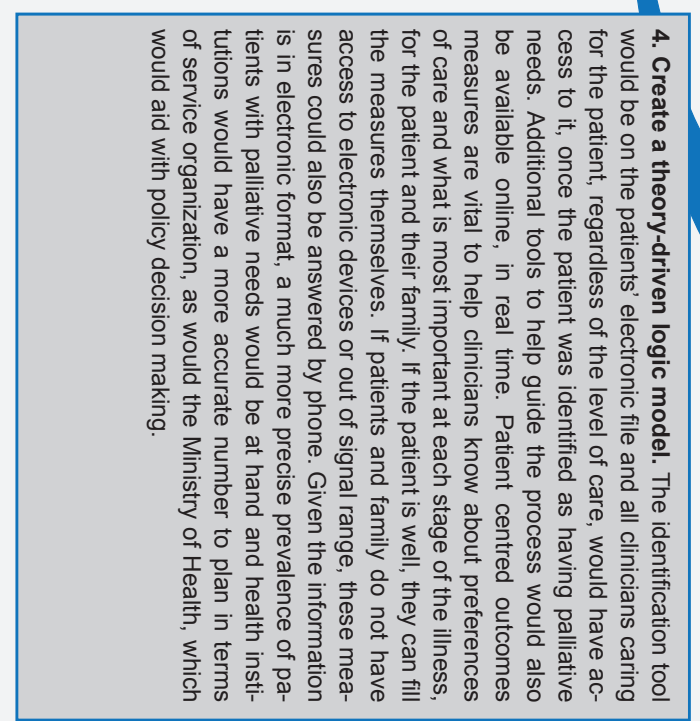

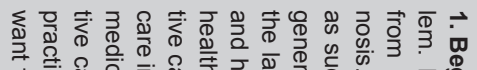

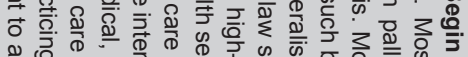

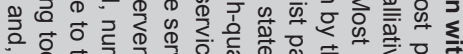

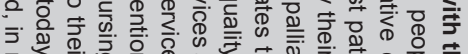
उై

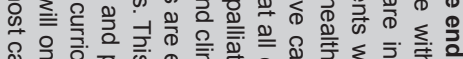

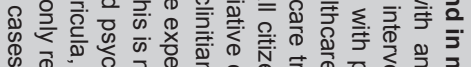
का

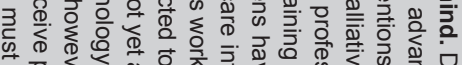

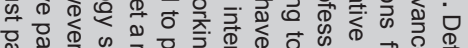

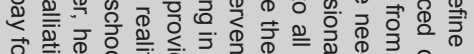

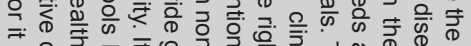

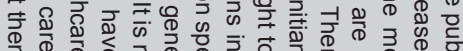

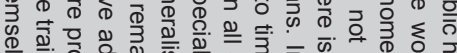

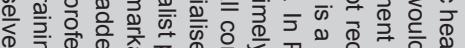
क.

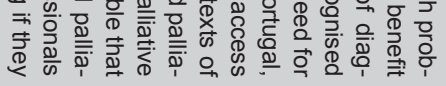

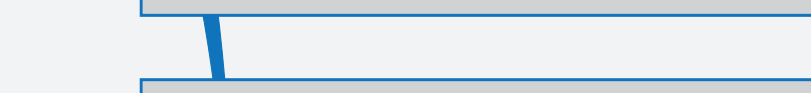

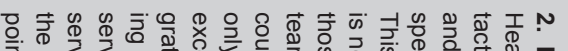

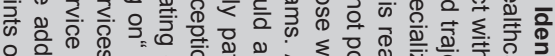

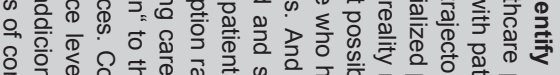

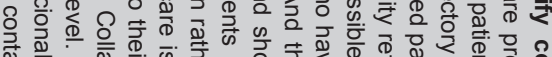

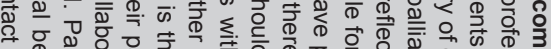

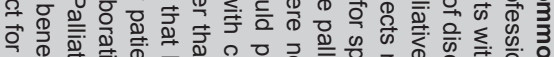

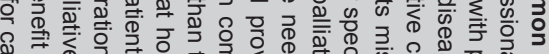
ঐ)

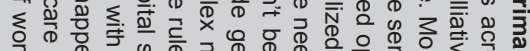

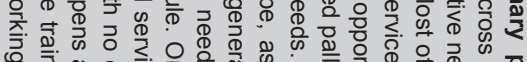

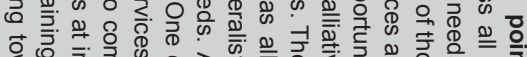

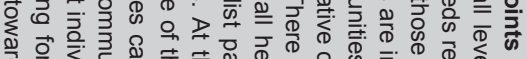

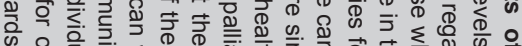

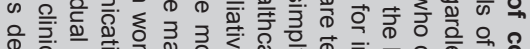

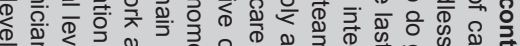
号

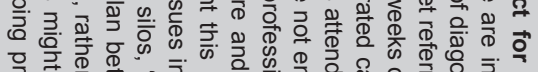
을 专

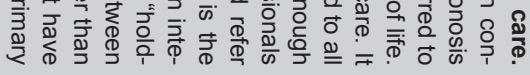

\section{1}

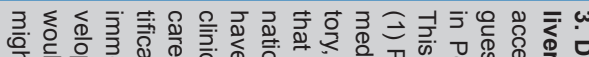

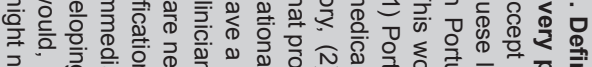

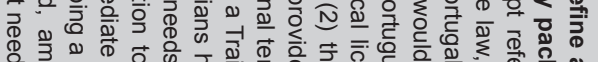

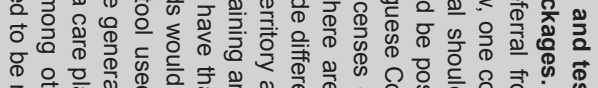

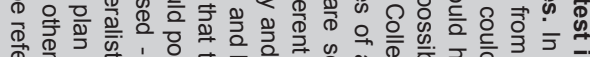

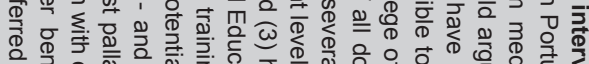

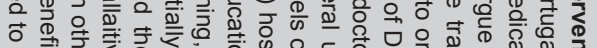

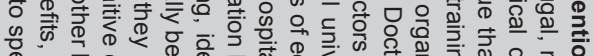

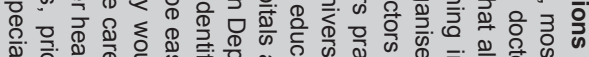

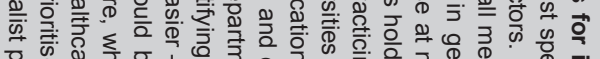
ग क

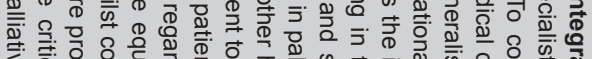

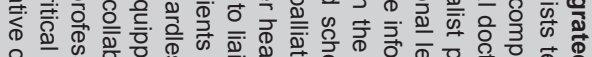

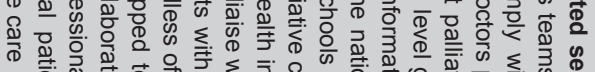

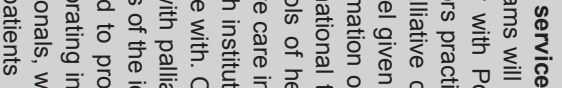

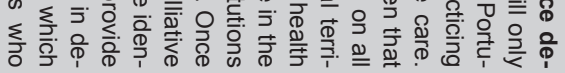


Based in our results, this was not the case. Clinicians lack training, and there are staff and time constraints alongside inexistence of institutional support. This is well aligned with a recent study from the European Association of Palliative Care underpinning the importance of education in knowledge development and skills acquisition in palliative care provision, ${ }^{49}$ as is with the Strategic Plan for the Development of Palliative Care in Portugal 2017 - 2018, in which training for clinicians, at different levels is proposed. ${ }^{50}$

The NASSS framework recognises that studies describing lists of facilitators and barriers concerning the implementation of innovative approaches in clinical practice are helpful and useful, but fail to theorise the failure to adopt, scale up, spread or sustain the innovation. ${ }^{15}$ Authors recommend the development of studies that are interdisciplinary, nondeterministic, locally situated, and designed to examine the relationship between human action and the wider organizational and system context. We feel we have achieved the latter, with our feasibility study, by relating all data generated from different sources.

Based on our findings, the measures selected altered clinicians' perception regarding patients with PC needs, and thus aiding in the decision to refer earlier and contributed directly to improved communication between the clinician and both patient and families. However, because there was only one participating department, results are not generalisable. The study design used was not feasible, but informative and comprehensive, as most departments did not participate due to attributes of complexity in health services research. Indeed, as Smets and Deliens propose “... health services research in palliative care and end-of-life care involves the study of palliative care needs, access and quality of palliative care, and the feasibility, effectiveness, and cost of palliative and end-of-life care services and interventions. The evaluation of services and interventions involving patients with advanced illness presents unique challenges, both ethical and methodological.". ${ }^{51}$ Indeed, there were undoubtedly a number of challenges occurring throughout the development of this work relating to organisational and interpersonal issues, funding and education. Our field notes, interim data collection period meeting and web-based survey data show that there is an urgent need to provide generalist PC training to clinicians.

\section{CONCLUSION}

There needs to be an integrated PC plan at institution level, alongside the development of a specialist hospitalbased PC team for clinical and research work. In order to conduct quality PC health services research, there needs to be contractual protected time for clinicians to conduct research, alongside clinical work. One could argue that legislating the provision of and access to PC by governments is not enough. There is a need for generalist PC training to clinicians working in hospitals. This could be part of an integrated PC plan at both country and institution level, alongside the existing development of specialist hospital-based
PC teams, to ensure timely provision of generalist PC to all in need and development of quality research work.

\section{ACKNOWLEDGMENTS}

To all patients who contributed for data collection our most profound appreciation. Without them this work would not have been possible. Thank you to all healthcare professionals and care teams who invited us to come and present the study to their service. A huge thank you to the participating healthcare professionals who performed data collection without whom this work would not have been possible.

\section{AUTHORS CONTRIBUTION}

BA: Design of the work, data acquisition, analysis and interpretation. Draft of the paper.

PPR, IJH, PLF: Conception and design of the study. Critical review of the paper.

\section{PROTECTION OF HUMANS AND ANIMALS}

This study was approved by the institutional ethics review board on the $8^{\text {th }}$ of august 2018, reference number 107-2018-1. The authors declare that the procedures were followed according to the Helsinki Declaration of the World Medical Association updated in 2013.

\section{DATA CONFIDENTIALITY}

The authors declare having followed the protocols in use at their working center regarding patients' data publication. Patient data were obtained directly from patients using paper format questionnaires by the participating healthcare professionals, which were entered into a deidentified electronic database by a research team member. Deidentified data are available for external researchers upon reasonable request.

\section{PATIENT CONSENT}

All participants signed an informed consent.

\section{COMPETING INTERESTS}

The authors declare that there are no conflicts of interest.

\section{FUNDING SOURCES}

Bárbara Antunes was funded by Foundation for Science and Technology (FCT) - Grant number PD/BD/113664/2015, Faculty of Medicine, University of Porto. The Doctoral Program Clinical and Health Services Research was funded by FCT - Grant number PD/0003/2013.

Currently Bárbara Antunes is funded by the National Institute for Health Research (NIHR) Applied Research Collaboration East of England (ARC EoE) programme. The views expressed are those of the author(s) and not necessarily those of the NHS, the NIHR or the Department of Health and Social Care. The funding organizations had no role in the design of the study, collection, analysis, interpretation of the data, or writing of the manuscript. 


\section{REFERENCES}

1. Firth AM, O'Brien SM, Guo P, Seymour J, Richardson H, Bridges C et al. Establishing key criteria to define and compare models of specialist palliative care: a mixed-methods study using qualitative interviews and Delphi survey. Palliat Med. 2019;33:1114-24.

2. Murtagh FE, Bausewein C, Verne J, Groeneveld El, Kaloki YE, Higginson IJ. How many people need palliative care? A study developing and comparing methods for population-based estimates. Palliat Med. 2014;28:49-58.

3. Murray SA, Kendall M, Mitchell G, Moine S, Amblas-Novellas J, Boyd K. Palliative care from diagnosis to death. BMJ. 2017;356:j878.

4. Gomez-Batiste X, Martinez-Munoz M, Blay C, Amblas J, Vila L, Costa $X$, et al. Identifying patients with chronic conditions in need of palliative care in the general population: development of the NECPAL tool and preliminary prevalence rates in Catalonia. BMJ Support Palliat Care. 2013;3:300-8

5. Maas EA, Murray SA, Engels Y, Campbell C. What tools are available to identify patients with palliative care needs in primary care: a systematic literature review and survey of European practice. BMJ Support Palliat Care. 2013;3:444-51.

6. Marcucci FC, Cabrera MA, Perilla AB, Brun MM, de Barros EM, Martins $\mathrm{VM}$, et al. Identification and characteristics of patients with palliative care needs in Brazilian primary care. BMC Palliat Care. 2016;15:51.

7. Mason B, Boyd K, Steyn J, Kendall M, Macpherson S, Murray SA. Computer screening for palliative care needs in primary care: a mixedmethods study. Br J Gen Pract. 2018;68:e360-9.

8. Meffert C, Rucker G, Hatami I, Becker G. Identification of hospital patients in need of palliative care-a predictive score. BMC Palliat Care. 2016;15:21.

9. Weissman DE, Meier DE. Identifying patients in need of a palliative care assessment in the hospital setting: a consensus report from the Center to Advance Palliative Care. J Palliat Med. 2011;14:17-23.

10. Scotland HI. Palliative care identification tools comparator. 2019. [accessed 2020 Nov 2]. Retrieved from https://ihub.scot/media/2079/ palliative-care-identification-tools-comparator.pdf.

11. Pina $P$, André $P$. Prevalência e características das pessoas com necessidades paliativas internadas em serviços hospitalares generalizados : contributo para a tradução e validação da ferramenta NECPAL-CCOMS-ICO@ para a população portuguesa. Lisboa: Universidade de Lisboa; 2018.

12. World Health Organization. Strategic considerations for strengthening the linkages between family planning and HIVIAIDS policies, programs, and services. 2009. [accessed 2020 Nov 4]. Retrieved from https:// www.who.int/reproductivehealth/publications/linkages/fp_hiv_strategic_ considerations.pdf.

13. Thompson DS, Fazio X, Kustra E, Patrick L, Stanley D. Scoping review of complexity theory in health services research. BMC Health Serv Res. 2016;16:87.

14. Greenhalgh T, Wherton J, Papoutsi C, Lynch J, Hughes G, A'Court C, et al. Beyond adoption: a new framework for theorizing and evaluating nonadoption, abandonment, and challenges to the scale-up, spread, and sustainability of health and care technologies. J Med Internet Res. 2017; 19 :e367.

15. Peters DH, Adam T, Alonge O, Agyepong IA, Tran N. Implementation research: what it is and how to do it. BMJ. 2013;347:f6753.

16. Peters DH, Tran NT, Adam T. WHO Implementation Research in Health: A Practical Guide. 2013. [accessed 2020 Sep 3]. Retrieved from: https:// www.who.int/alliance-hpsr/resources/implementationresearchguide/en/.

17. Eldridge SM, Lancaster GA, Campbell MJ, Thabane L, Hopewell S, Coleman CL, et al. Defining feasibility and pilot studies in preparation for randomised controlled trials: development of a conceptual framework. PLoS One. 2016;11:e0150205.

18. Hagen NA, Biondo PD, Brasher PM, Stiles CR. Formal feasibility studies in palliative care: why they are important and how to conduct them. J Pain Symptom Manage. 2011;42:278-89.

19. Orsmond GI, Cohn ES. The distinctive features of a feasibility study: objectives and guiding questions. OTJR. 2015;35:169-77.

20. Oken MM, Creech RH, Tormey DC, Horton J, Davis TE, McFadden ET, et al. Toxicity and response criteria of the Eastern Cooperative Oncology Group. Am J Clin Oncol. 1982;5:649-55.

21. Helleso R, Melby L, Hauge S. Implications of observing and writing field notes through different lenses. J Multidiscip Healthc. 2015;8:189-97.

22. Maharaj N. Using field notes to facilitate critical reflection. 2016. [accessed 2018 Juç 25]. Retrieved from: http://dx.doi.org/10.1080/146 23943.2015.1134472.
23. Phillippi J, Lauderdale J. A guide to field notes for qualitative research: context and conversation. Qual Health Res. 2018;28:381-8.

24. Antunes B, Ferreira PL. Validation and cultural adaptation of the Integrated Palliative care Outcome Scale (IPOS) for the Portuguese population. BMC Palliat Care. 2020;19:178.

25. Ferreira PL, Antunes B, Barros Pinto A, Gomes B. Cuidados de fim de vida: Portugal no projeto europeu PRISMA. Rev Port Saúde Pública. 2012;30:62-70

26. Murtagh FE, Ramsenthaler C, Firth A, Groeneveld El, Lovell N, Simon ST. A brief, patient- and proxy-reported outcome measure in advanced illness: Validity, reliability and responsiveness of the Integrated Palliative care Outcome Scale (IPOS). Palliat Med. 2019;33:1045-57.

27. Antunes B, Rodrigues PP, Higginson IJ, Ferreira PL. Determining the prevalence of palliative needs and exploring screening accuracy of depression and anxiety items of the integrated palliative care outcome scale - a multi-centre study. BMC Palliat Care. 2020;19:69

28. Faria de Sousa $P$, Juliao M. Translation and validation of the Portuguese version of the surprise question. J Palliat Med. 2017;20:701.

29. Masso M, Allingham SF, Banfield M, Johnson CE, Pidgeon T, Yates P, et al. Palliative care phase: inter-rater reliability and acceptability in a national study. Palliat Med. 2015;29:22-30.

30. Higginson IJ, Booth S. The randomized fast-track trial in palliative care: role, utility and ethics in the evaluation of interventions in palliative care? Palliat Med. 2011;25:741-7.

31. Eysenbach G. Improving the quality of web surveys: the Checklist for Reporting Results of Internet E-Surveys (CHERRIES). J Med Internet Res. 2004;6:e34.

32. Reynolds EG, Sutherland HW. A systematic approach to the planning, implementation, monitoring, and evaluation of integrated health services. BMC Health Serv Res. 2013;13:1-11.

33. World Medical Association. WMA Declaration of Helsinki - Ethical Principles for Medical Research Involving Human Subjects. 2013. [accessed 2017 Jun 25]. Retrieved from https://www.wma.net/policiespost/wma-declaration-of-helsinki-ethical-principles-for-medicalresearch-involving-human-subjects/.

34. Vaismoradi M, Turunen $\mathrm{H}$, Bondas $\mathrm{T}$. Content analysis and thematic analysis: implications for conducting a qualitative descriptive study. Nurs Health Sci. 2013;15:398-405.

35. Craig P, Dieppe P, Macintyre S, Michie S, Nazareth I, Petticrew M, et al. Developing and evaluating complex interventions: the new Medical Research Council guidance. BMJ. 2008;33:a1655.

36. Craig P, Petticrew M. Developing and evaluating complex interventions: reflections on the 2008 MRC guidance. Int J Nurs Stud. 2013;50:585-7.

37. Moore GF, Audrey S, Barker M, Bond L, Bonell C, Hardeman W, et al. Process evaluation of complex interventions: Medical Research Council guidance. BMJ. 2015;350:h1258.

38. Higginson IJ, Evans CJ, Grande G, Preston N, Morgan M, McCrone P. Evaluating complex interventions in end of life care: the MORECare statement on good practice generated by a synthesis of transparent expert consultations and systematic reviews. BMC Med. 2013;11:111.

39. Oliveira A, Ferreira PL, Antunes B, Pimentel FL. Qualidade de vida em oncologia: dispositivo digital de recolha de dados. Acta Med Port. 2010;23:1017-24.

40. Addington-Hall JM, Bruera E, Higginson IJ, Payne S. Research methods in palliative care. Oxford: Oxford University Press; 2007.

41. Oishi A, Murtagh FE. The challenges of uncertainty and interprofessional collaboration in palliative care for non-cancer patients in the community: a systematic review of views from patients, carers and health-care professionals. Palliat Med. 2014;28:1081-98.

42. Carmont SA, Mitchell G, Senior H, Foster M. Systematic review of the effectiveness, barriers and facilitators to general practitioner engagement with specialist secondary services in integrated palliative care. BMJ Support Palliat Care. 2018;8:385-99.

43. Gardiner C, Gott M, Ingleton C. Factors supporting good partnership working between generalist and specialist palliative care services: a systematic review. Br J Gen Pract. 2012;62:e353-62.

44. Rasoal D, Kihlgren A, Skovdahl K. Balancing different expectations in ethically difficult situations while providing community home health care services: a focused ethnographic approach. BMC Geriatr. 2018;18:312.

45. Mercadante S, Gregoretti C, Cortegiani A. Palliative care in intensive care units: why, where, what, who, when, how. BMC Anesthesiol. 2018;18:106.

46. Nelson JE, Bassett R, Boss RD, Brasel KJ, Campbell ML, Cortez TB, et al. Models for structuring a clinical initiative to enhance palliative care in 
the intensive care unit: a report from the IPAL-ICU Project (Improving Palliative Care in the ICU). Crit Care Med. 2010;38:1765-72.

47. Bharmal A, Morgan T, Kuhn I, Wee B, Barclay S. Palliative and end-oflife care and junior doctors': a systematic review and narrative synthesis. BMJ Support Palliat Care. 2019:bmjspcare-2019-001954.;

48. Portugal. Lei n. ${ }^{\circ}$ 52/2012. Diário da República, I Série, n. ${ }^{\circ} 172$ (2012/09/05). p.5119-24..

49. Paal P, Brandstotter C, Lorenzl S, Larkin P, Elsner F. Postgraduate palliative care education for all healthcare providers in Europe: Results from an EAPC survey. Palliat Support Care. 2019;17:495-506.
50. Comissão Portuguesa de Cuidados Palaitivos. Plano Estratégico para o Desenvolvimento dos Cuidados Paliativos Biénio 2017-2018. [accessed 2021 Jan 23]. Retrieved from: https://www.sns.gov.pt/wp-content/ uploads/2016/11/Plano-Estrat\%C3\%A9gico-para-o-DesenvolvimentoCP-2017-2018-2.pdf.

51. Smets $T$, Deliens L. Health services research in palliative care and endof-life care in Oxford Textbook of Palliative Medicine. Cherny N, Fallon M, Kaasa S, Portenoy RK, Currow DC, editors. $5^{\text {th }}$ ed. Oxofrd: Oxford University Press; 2015. 